\title{
LA IWW Y EL MOVIMIENTO OBRERO EN CHILE: EL CASO DE LOS OBREROS PORTUARIOS NORTINOS (1919-1923)
}

\author{
THE IWW AND THE WORKERS MOVEMENT IN CHILE: THE CASE \\ OF THE NORTHERN DOCKWORKERS (1919-1923)
}

\author{
Camilo A. Santibáñez Rebolledo*
}

\begin{abstract}
Mediante el examen de la conflictividad laboral en los puertos nortinos de Iquique y Antofagasta, este artículo busca desmontar la atribución historiográfica que le concede a los Industrial Workers of the World (IWW), la organización y dirección de las principales huelgas en los terminales marítimos chilenos entre 1919 y 1923. Según se concluye, el rol de esta organización en la propensión huelguística de los hombres ocupados en la estiba ha sido sobredimensionado por los investigadores, cuestión que obedecería a insuficiencias de rigurosidad en el tratamiento de la documentación y de la terminología laboral, e igualmente en la falta de consideración de la coyuntura 1919-1923 como parte de un largo derrotero huelguístico que los estibadores nortinos habían exhibido desde el siglo XIX, particularmente en lo referido a métodos y demandas obreras.
\end{abstract}

Palabras claves: Historia del movimiento obrero chileno, IWW, obreros portuarios.

This paper seeks to dismantle the historiographical attribution that gives the Industrial Workers of the World (IWW) the organization and direction of the main strikes in the Chilean maritime terminals of Iquique and Antofagasta between 1919 and 1923. It is concluded that the role of this organization in the strike propensity of stevedores has been oversized by researchers. It is concluded that the role of this organization in the striking propensity of the dockworkers has been oversized by researchers, a problem that would be due to insufficient rigor in the treatment of documentation and labor terminology, as well as the lack of consideration of the conjuncture 1919-1923 as part of a long road that this workers had exhibited from the nineteenth century, particularly in regard to methods and demands.

Key words: History of the chilean workers movement, IWW, dockworkers.

\section{Introducción ${ }^{1}$}

Aunque con matices, prácticamente la totalidad de los historiadores del movimiento obrero chileno ha referido la importancia de los Industrial Workers of the World en los conflictos laborales que estallaron en el país durante 1919 y 1923. Dichos investigadores coincidieron también en que, desde su formación en Chile, las ideas foráneas de los IWW habrían arraigado de manera particularmente temprana e incidente en la "gente de mar"; es decir, sobre la fuerza de trabajo ocupada en los muelles, bodegas y buques de los puertos nacionales. Por esta razón, y extrapolando casos como las huelgas marítimas y portuarias de Valparaíso en 1921, tendió a asumirse que los conflictos detonados en el resto de la costa nacional durante el mismo período habían sido provocados y conducidos por los wobblies ${ }^{2}$.

Los muelles salitreros no escaparon a dicha suposición. Según Jorge Barría, por ejemplo, la huelga para exigir la implantación de un sistema de repartición del trabajo portuario en Iquique, denominado "la redondilla", habría significado la paralización de las faenas de "todo el litoral norte" a mediados de 1920, debido a que los trabajadores "[estaban] agrupados en federaciones obreras marítimas influidas por los militantes de la IWW". Tres años más tarde, la larga huelga para protestar por la derogación del referido sistema corroboraría dicha impresión, porque el conflicto había sido ocasionado por la expulsión de un dirigente portuario que, en efecto, pertenecía a la IWW (1960:289, 321-322) ${ }^{3}$. En el intertanto, siguiendo a Peter DeShazo, la contraofensiva patronal que había sido liberada en 1921 con el mismo objeto, había tenido por propósito "[aniquilar] el poder y la influencia de la IWW entre los estibadores y los trabajadores portuarios de Antofagasta, Valparaíso y Talcahuano". En Iquique, según el historiador norteamericano, donde el citado sistema había sobrevivido a dicha

\footnotetext{
* Programa de Doctorado en Historia de la Universidad de Santiago. Santiago, Chile. Correo electrónico: sntibaez@ gmail.com
} 
ofensiva, "continuó beneficiando a la IWW y a su aliada, la Federación Obrera Marítima", hasta los sucesos de 1923 (2007:81-82). Julio Pinto y Verónica Valdivia, por su parte, sostuvieron que la huelga de este último año, que terminó con la redondilla en Iquique, había sido provocada por el gobernador marítimo local, con el propósito de "[suprimir el sistema rotativo, y propinarle] a la IWW tarapaqueña un [duro] golpe" (2001:94). Finalmente, la tesis más reciente al respecto, escrita por Alejandra Saavedra e intitulada "La IWW y su rol en el movimiento obrero 1919-1927: Iquique, Antofagasta y Valparaíso", concluyó que este ciclo huelguístico por la redondilla se había convertido en "un [arduo] conflicto de carácter nacional", debido a "la vinculación expresa de los gremios de mar a las filas anarquistas y más propiamente anarcosindicalistas relacionadas con la IWW" (2005:109-110).

Basados en el estudio de la conflictividad laboral protagonizada por los estibadores de los principales puertos de la región salitrera durante 1919-1923 -evidentemente centrada en el asunto de la redondilla-, las líneas siguientes critican la enunciada atribución historiográfica respecto del liderazgo industrialista en los muelles de Iquique y Antofagasta. La hipótesis que se busca probar, en cambio, propone que durante el período citado tanto los métodos como las demandas exhibidas por los estibadores de dichos terminales precedían al surgimiento de la IWW, y que el rol y la presencia de esta organización obrera en la costa nortina fue en realidad bastante más accidentada que lo sugerido por los historiadores.

Para documentar dicha hipótesis se ha revisado minuciosamente la prensa obrera y parte de la papelería gubernamental del mismo período, e igualmente se ha acudido a la literatura acerca de la conflictividad laboral en los frentes de atraque mencionados. Gracias a estas revisiones es posible sostener que la criticada atribución fue resultado de tres deficiencias historiográficas: la prescindencia de la exhaustividad documental o la escasa rigurosidad en el tratamiento de las fuentes; la falta de consideración de la coyuntura 1919-1923 como parte del largo derrotero huelguístico que los estibadores nortinos exhibieron desde el siglo XIX, particularmente en lo referido a métodos y demandas; y los problemas para diferenciar los distintos oficios que componían la fuerza de trabajo en las faenas de embarque marítimo, común y genéricamente referidos bajo el rótulo "gente de mar".
El apartado a continuación revisa brevemente la conflictividad laboral precedente a la IWW en los puertos de la región salitrera, con el propósito de demostrar que los métodos y las demandas obreras que marcaron la coyuntura 1919-1923 habían sido largamente maceradas en este sector y expresadas de modo reiterado. El apartado subsiguiente, en tanto, examina con detención las huelgas de 1919-1923, centrándose en la presencia y el rol jugado por la IWW en dichos conflictos.

\section{Métodos y demandas obreras en los puertos nortinos precedentes a la IWW}

La observación de las huelgas portuarias acontecidas en la región salitrera durante el medio siglo que antecede al auge y declive de la IWW en Chile, sugiere ciertos patrones de continuidad relevantes en los métodos y las demandas esgrimidas por los trabajadores. En lo que a Tarapacá refiere, Julio Pinto Vallejos documentó numerosas paralizaciones portuarias ocurridas durante el último tercio del siglo XIX. Una de las más relevantes ocurrió a mediados de 1873, en Pisagua, al amotinarse los cargadores y lancheros como reacción a los intentos de la Empresa del Ferrocarril por trabajar con obreros no matriculados; condición gremial para desarrollarse en estas faenas durante buena parte de dicho siglo ${ }^{4}$. Una segunda huelga importante aconteció en Iquique durante 1893, liderada por la Gran Unión Marítima y también "en defensa de la exclusividad laboral de sus asociados". Cuestión significativa, considerando que los gremios de jornaleros y lancheros habían sido oficialmente derogados tras la huelga general de 1890; paralización laboral iniciada y dirigida precisamente por estos mismos obreros (1998:174-181, 221-222). En Antofagasta, a mediados de 1903 -unos meses después de la célebre huelga marítima y portuaria de Valparaíso ${ }^{5}$-, la Mancomunal de dicho puerto se enfrascaría en un conflicto con los contratistas, "al tomar por su propia cuenta los trabajos de embarque y desembarque", desplazando a los agentes intermediarios. Estos últimos, sin embargo, consiguieron empujar a los trabajadores a la huelga primero, y el sofocamiento militar del conflicto luego, recobrando el control de la contratación y diezmando la iniciativa obrera (Recabarren 1954:259-260; Parker et al. 1985:45-47).

La misma demanda surgió una década más tarde, durante 1916, en el puerto de Iquique. Según 
el informe gubernamental, los trabajadores estaban demandando "la exclusión del contratista Campbell en la carga de las naves y su reemplazo por el sindicato de jornaleros y estivadores" ( sic); es decir, "que en adelante los capitanes de buque no pudieran contratar sino con el sindicato" (Oyarzún et al. 1917:8-11). Para cuando los trabajadores decretaron la huelga, no obstante, las fuerzas de la marinería y del ejército habían sido puestas a disposición de las casas embarcadoras por el gobierno, y los trabajadores volvieron a fracasar ${ }^{6}$. En julio del año siguiente, reunidos en el Primer Congreso Marítimo, en Valparaíso, los obreros de Arica, Caleta Buena, Iquique, Mejillones, Antofagasta, San Antonio, Talcahuano y Punta Arenas emitieron una proclama que, junto con declarar la huelga contra la fotografía forzosa que el gobierno estaba imponiendo a los trabajadores, exigía "la abolición de los contratistas e intermediarios en las faenas marítimas, y el reconocimiento por parte de los armadores de la Oficina del Trabajo que será necesaria crear en cada puerto para reemplazar a aquellos" (Parker et al. 1985:76-77).

La segunda Convención de la IWW, celebrada cuatro años más tarde, durante mayo de 1921 en Valparaíso, no haría sino ratificar las aspiraciones de aquel Congreso de 1917. Entre los acuerdos de 1921 figuraban: "Tratar de abolir el sistema de contrato y especialmente los contratistas en las faenas marítimas" y "luchar por imponer el sistema de redondillas en [tales] faenas" (Parker et al. 1985:83). Sistema que, para entonces, había sido instaurado en los puertos de Antofagasta e Iquique, en 1919 y 1920, respectivamente (Santibáñez 2015).

En los puertos en que la redondilla no fue implantada, pero tampoco fue fundada la IWW, las fricciones por el control de la contratación se siguieron presentando. En Pisagua por ejemplo, durante abril de 1923, los obreros portuarios "rompieron" con los consignatarios y contratistas por no respetar estos las tarifas acordadas. Al día siguiente, "[tomaron] el trabajo directamente [y nombraron] un representante que se entendiera con los capitanes de las naves, prescindiendo en absoluto de los contratistas". El subdelegado marítimo decretó "la prohibición de tomar los trabajos" y la suspensión de cuatro trabajadores, desatando la huelga. "Hemos resuelto no volver a las faenas", señalaron los obreros, "intertanto se mantenga el decreto de suspensión a unos y castigo a otros y mientras se pretenda imponernos contratistas", a quienes responsabilizaban de quedarse con parte del salario y provocar conflictos de modo reiterado ("El movimiento en Pisagua", Federación Obrera Marítima de Pisagua, 7 de mayo de 1923; Pinto y Valdivia 2001:92).

Resulta patente, por tanto, que la reivindicación obrera por monopolizar el trabajo portuario había germinado de los rescoldos gremiales decimonónicos, y había seguido manifestándose periódicamente en los distintos puertos de la zona salitrera (y también fuera de ella). Igualmente evidente resulta el hecho de que, pese a sus inciertos resultados, la paralización de faenas fue el método predilecto de los trabajadores en los conflictos que dicha reivindicación detonó. Ambas cuestiones configuraban el derrotero al que arribaría la IWW en los puertos salitreros a fines de la segunda década del siglo XX, y seguirían presentándose en aquellos terminales en los que el industrialismo no llegó a constituirse.

El apartado siguiente indaga en el modo en que dicho arribo aconteció; en medio de distintos impulsos organizativos, una hostil disputa ideológica por la conducción del movimiento obrero regional, y el desigual itinerario tomado por los diferentes gremios de oficio que componían la fuerza de trabajo portuaria en el embarque del salitre. Factores que, entre 1919 y 1923, configuraron un panorama bastante más complejo que el esbozado por la historiografía en lo referido a los muelles nortinos.

\section{Las huelgas de 1919-1923, los estibadores y la IWW}

Entre fines de 1919 e inicios de 1920 hubo un resurgimiento de las organizaciones obreras portuarias en la región salitrera; previamente arrasadas, tras el ciclo huelguístico de 1916-1917. En Iquique, el 25 y 26 de diciembre se fundan el Gremio de Jornaleros Marítimos y el de Estibadores Marítimos respectivamente, y a inicios de marzo se instituye la Federación Obrera Marítima de Tarapacá, siguiendo los pasos de los portuarios de Antofagasta, donde los trabajadores habían organizado recientemente la propia (Archivo de la Intendencia de Tarapacá [ITAR], 1234, legajos 78-79). No resulta sencillo, sin embargo, atribuir las responsabilidades tras dichos esfuerzos. En un documento policial fechado en abril de 1919, por ejemplo, se daba cuenta de cómo el fundador del Partido Obrero Socialista, Elías Lafferte, presente 
en una reunión de "cargadores, lancheros, etc.", había tomado la palabra para indicar que el objeto de la convocatoria era "que vuelvan los obreros a unificarse por ser lla el tiempo preciso i nombrar un directorio estable para así dirijir los destinos de la Federación Obrera [de Chile (FOCH)]" (sic) (ITAR 1144, legajo 93). Sin embargo, según señalaban los anarquistas parapetados en El Surco, los gremios de cargadores y lancheros que eran parte de la FOCH la habían abandonado hacia fin de año, porque los socialistas habían "traspasado el local que la Federación había arrendado, a la dirección del Partido, sin haber consultado a los gremios" ("Rompimiento", 21 de noviembre de 1919). En Antofagasta, en tanto, también hacia fines de 1919, la Federación Obrera Marítima provincial (FOM) había conseguido subir las tarifas, e inclusive instar al municipio de Antofagasta a "retirar todos los burdeles que [expedían] bebidas alcohólicas cerca de las faenas marítimas", bajo la amenaza de una paralización portuaria general. Según afirmaban alborozados los anarquistas iquiqueños, la FOM de Antofagasta había conseguido no solamente erigirse apartada del alero de la FOCH antofagastina, sino inclusive remover al jefe de muelle de la Nitrate Agencies durante el mismo 1919: un socialista llamado Florindo Venegas ("De Antofagasta", El Surco, 21 de noviembre de 1919).

Durante octubre del mismo 1919, como puede leerse en un número desafortunada y severamente mutilado del periódico iquiqueño El Surco, la IWW había hecho llegar a los puertos salitreros el llamamiento a participar en una convención. "El siempre creciente poder de [la] clase capitalista" sostenía el escrito, "nos ha hecho reaccionar sobre este anticuado sistema de organización obrera"; "hemos tomado como base, la constitución de los Industrial Workers of the World [para superar] esa vieja táctica de luchar en pequeños grupos, esperando que un diputado, senador, presidente de la República, autoridades, juntas arbitrales u otros agenos a proporcionar lo que nosotros por medio de la union debemos exigir" (sic) ("A las organizaciones obreras y trabajadores de la Región chilena", 29 de octubre de 1919).

Los historiadores que hasta ahora han investigado el origen de esta organización entre los obreros chilenos, han coincidido en que su arranque fue gestado principalmente por los obreros marítimos y portuarios en Valparaíso entre 1918 y 1919. En particular, según Víctor Muñoz y Peter DeShazo, a partir de la relación establecida entre el Sindicato de Estibadores de Valparaíso y los tripulantes de la Marine Transport Workers Industrial Union de la IWW de Nueva York, Chicago y California. Tras madurar "en el interior de un congreso de la Sociedad Gremial de Gente de Mar", celebrado durante 1918, estos gestores habrían propuesto una convención fundacional, que finalmente aconteció entre el 24 y el 27 de diciembre de 1919 en Santiago. De esta surgió la sección chilena de la IWW; primero en Valparaíso y Viña del Mar, y luego, afirman los autores, desde Iquique hasta Corral, incluyendo puertos como Antofagasta, con diferente perdurabilidad (Muñoz 2013:107; DeShazo 2007:225) 7 .

No obstante, un estudio de documentos posteriores de la propia IWW permite saber que el proceso de enraizamiento en los puertos salitreros fue mucho más dificultoso. En el caso de Antofagasta, los industrialistas reconocían sin pretextos que, tras la convención de 1919, "no se llegó a echar a las bases de la Unión Local I.W.W.”, y que en Iquique, José N. Díaz, el delegado de los Gremios de Lancheros y Cargadores no había sido admitido a su retorno de la convención, pese al boicot que los gremios aludidos iniciaron para revertir la medida. Cuestión que dejó a Díaz y a la IWW al margen de aquellas faenas ("El criterio de los obreros organizados", $E l$ Despertar de los Trabajadores, 2 y 4 de febrero y 28 de enero de 1922).

Aunque es confusa, otra documentación corrobora esta impresión. Por ejemplo, según se lee en un telegrama enviado a mediados de 1920 por socialistas del norte hacia la zona carbonífera, mientras que los "marítimos" de Mejillones, Taltal, Coloso, Tocopilla y Arica pertenecían a la FOCH, los de Antofagasta e Iquique eran "autónomos"; "[desmintiendo] enérjicamente" pertenecer a la IWW. Lo que significaba, para el remitente, que "no [había] tal de la gran organizacion que [la IWW decía tener] en la rejion norte" (sic) ("Telegramas", La Jornada, 25 de julio de 1920).

Pese a que, en la misma fecha, la policía relacionaba las "sucesivas huelgas o paros jenerales [en la costa salitrera]" (sic) con la IWW, y a que los obreros del Consejo Federal de Mejillones serían encarcelados por el mismo motivo (ITAR 1169, legajo 111; "La represión contra los obreros organizados", El Socialista, 26 de septiembre de 1920), la llegada de "tres anarquistas procedentes de Valparaíso y Antofagasta" a Iquique, durante marzo 
de 1921, instando a otros obreros a "incorporarse a la IWW" y a fortalecer al proletariado, refuerza la idea de que, en efecto, dicha organización había fracasado en su primer esfuerzo por radicarse en el puerto nortino (Pinto y Valdivia 2001:94). Por otra parte, durante el mismo 1920, hacia fines de agosto, la Convención Obrera Marítima que celebraron en Iquique las Federaciones Obreras Marítimas de dicho puerto y de Antofagasta, prueba que estos trabajadores bregaban y mantenían el robustecimiento de sus organizaciones al margen de la IWW.

Los pocos documentos con que se cuenta de estas Federaciones tampoco hacen suponer ningún arraigo de los industrialistas entre sus filas antes de 1921. Sí arrojan ciertas luces, sin embargo, respecto de las posibles expectativas que empujaron a los obreros de los muelles iquiqueños a participar en la Segunda Convención de la IWW, unos meses luego de la visita de "los tres anarquistas" aludidos en el párrafo anterior, y a fundar luego una Unión Local de la IWW y su propio órgano de prensa $(E l$ Productor). Por ejemplo, en los párrafos fundamentales de un artículo publicado durante mayo de 1921 en El Despertar de los Trabajadores, la Federación Obrera Marítima de Iquique sostuvo, en alusión a las elecciones parlamentarias, la FOCH y el POS:

La F.O.M. compuesta por sus diferentes gremios, pone en conocimiento del pueblo de Tarapacá y a toda la República, que es completamente ajena a todo movimiento político. Como comprenderan todos los compañeros que la organizacion es un conjunto eterojéniés y de todas las escuelas ideológicas, los organismos obreros no pueden apoyar determinada tendencia porque seria romper su unidad de accion; para evitar desmoralizacion en sus filas tiene como norma de la autonomía de sus asociados, pudiendo fuera del organismo obrar segun su modo de pensar. Todos saben que los obreros de esta provincia hemos sostenido rudas batallas rechazando la política oficial dentro de los organismos. Hacen mas ó menos diez años que se puso bien en claro la no aceptación de la manzana de la discordia (la política) y los mismos que hoy dia se forzan porque los apoyemos en sus pretensiones estuvieron de acuerdo con nosotros en rechazarla. (sic)
("Colectividades unificadas de Tarapacá",

8 de mayo de 1921)

En lo referido a Antofagasta, y debido a la escasez de documentación, la contraofensiva patronal contra la IWW de Valparaíso, iniciada en agosto de 1921, permite dar cuenta de la compleja situación en la que se hallaban los gremios marítimos y portuarios durante el mismo período ${ }^{8}$. Según indican las fuentes, la instauración de la redondilla había impulsado a una naciente Asociación de Gremios Unidos de Estibadores i Jornaleros Marítimos a intentar monopolizar el trabajo en los muelles; objeto para el que habían celebrado "un convenio de ajencia, comision i mandato" ( sic) con dos hombres que se convirtieron en sus representantes para la contratación de carga, estiba y desestiba de buques en Antofagasta y Coloso. Sin embargo, tras la declaración de huelga en solidaridad con los portuarios de Valparaíso hecha por los lancheros a inicios de septiembre, y el lockout con el que las casas embarcadoras respondieron, la redondilla fue abolida en Antofagasta por la Gobernación Marítima, afectando primordialmente a los jornaleros y estibadores que se regían por esta forma de organizar el trabajo desde 1919; a diferencia, por cierto, de los lancheros y movilizadores del mismo puerto ("Antofagasta", El Despertar de los Trabajadores, 8 de septiembre de 1921). Por lo mismo, así como señalaba un diputado en una comunicación enviada al Ministerio del Interior y a la Oficina del Trabajo, la abolición de la redondilla iba a significar la cesantía de un número importante de "jornaleros i estibadores", pese a su esfuerzo por garantizar el normal funcionamiento de las faenas (Telegrama de Leonardo Guzmán al Director de la Oficina del Trabajo, Archivo Nacional de la Administración [ARNAD], Oficina del Trabajo, Vol. 70, III, Antofagasta, 16 de septiembre de 1921).

¿Cómo podía explicarse esta cuestión? Según narró la propia IWW más tarde, para agosto de 1921, jornaleros y estibadores se habían empecinado en conseguir la abolición de los contratistas, apoyándose en "medios legales y parlamentarios" para legalizar la personería jurídica de un contrato de carga y descarga de vapores. La crónica señala que estos obreros contaban con un apoyo incondicional de "varios políticos y personas influyentes en las esferas gubernativas, que aleccionaron a los trabajadores fraccionándolos"; motivo por el que jornaleros y estibadores fundaron la "Asociación de 
Gremios Unidos". En este punto estalló el lockout de la Asociación de Comerciantes en Valparaíso, pero la Asociación de Gremios Unidos no expresó ninguna solidaridad. Los gremios de lancheros y movilizadores, en cambio, iniciaron el boicot que fue sofocado con el ya referido lockout patronal en todas las faenas marítimas, abriendo la Bolsa de Trabajo y declarando que no admitiría federados en las faenas. Los jornaleros y estibadores, quejándose del retorno a las fauces de los contratistas, alegaron que la medida los afectaría únicamente a ellos; los únicos que "[se habían] puesto respetuosamente al servicio de la autoridad, contribuyendo a no prestar ninguna clase de apoyo a los gremios en huelga" ("El criterio de los obreros organizados", El Despertar de los Trabajadores, 4, 5 y 7 de febrero de 1922).

En los muelles de Iquique, mientras, las notas de la policía daban cuenta de una reunión celebrada en el local de la Federación Obrera Marítima, el 6 de septiembre, "con asistencia de tres delegados de la I.W.W." que habían llegado hacía un par de días desde Valparaíso con el objeto de "ponerse de acuerdo para boicotear los vapores que [arribaran] a este puerto". Sin embargo, según el agente de pesquisas, "la opinión casi unánime de los trabajadores [era] contraria a esta idea, por la crítica situación pecuniaria en que se [encontraban]" (ITAR 1234, legajo 171).

Si bien el levantamiento de la IWW iquiqueña parece haber sido esfuerzo de gremios portuarios como el de jornaleros, hacia el segundo semestre del mismo año dichos obreros habían abandonado el local de los industrialistas, por la prohibición que estos últimos decretaron respecto del velatorio de un trabajador en el inmueble, aduciendo razones ideológicas ("El criterio de los obreros organizados", El Despertar de los Trabajadores, 28 y 31 de enero de 1922). En el contexto de la inminente derogación de la redondilla, y debido a que los jornaleros habían continuado enviando un delegado a las reuniones de la IWW, los wobblies le solicitaron a dichos obreros que se retiraran de la Unión Local, pues habían "recurrido a los distintos partidos [desconociendo] la fuerza del proletariado organizado"; seguramente buscando la protección del referido sistema de contratación. Por esto último, los jornaleros reaccionaron apuntando a los wobblies como traidores que los abandonaban en el preciso momento que se hallaban al borde de un conflicto (ITAR 1220, legajo 69).
La crisis de la industria salitrera que estos sucesos tenían por escenario afectó duramente a los otros gremios portuarios, desestabilizando la Unión Local desde fines de 1921 y hasta inicios de 1923. Principalmente por la depuración que las casas embarcadoras realizaron en las cuadrillas, gracias a la cesantía provocada por la disminución de las exportaciones. Hacia este último período, El Productor señalaba las dificultades que sufría para corporizarse entre los cargadores y lancheros. Entre estos últimos, el gremio había sido mantenido por un pequeño grupo de hombres, que debieron soportar las arbitrariedades en la asignación de turnos y el pago de los mismos por parte de los capataces; misma ola de hostigamientos que los había arrojado de vuelta a la IWW ("A propósito de la cesantía forzosa", "Unión Local I.W.W.", 27 de enero de 1923) $)^{9}$. Pese a que en el caso de los cargadores el reclutamiento fue más tortuoso, para marzo de 1923 los industrialistas habían conseguido organizar la Subdivisión de Cargadores y la de Lancheros, y para mediados de mayo ambas firmaban una amenaza de huelga general en defensa de los operarios de Pisagua, junto a los Carpinteros de Ribera, Calafates y de Oficios Varios, además de los Gremios de Jornaleros Marítimos y el de Estibadores ${ }^{10}$.

Esta reanimación del sindicalismo en los muelles avivó también las preocupaciones de las autoridades locales. Para agosto, el gobernador marítimo escribía sus quejas convencido de que la huelga de jornaleros en curso, producida por el nombramiento de un inspector obrero, era responsabilidad de la IWW; "que [había] logrado tomar cuerpo entre los obreros marítimos, gracias a la facilidad que [ofrecía] la 'redondilla' y su semejanza con un verdadero Soviet en el trabajo" (ITAR 1203, legajo 147). Sin embargo, contrariando sus cálculos y para desánimo de wobblies y comunistas, los indicios documentales sugieren mucho menor arraigo del ideario industrialista entre dichos trabajadores. En el balance acerca del conflicto que realizó el periódico anarquista El Sembrador, por ejemplo, al mismo tiempo que glorificaban el levantamiento de los jornaleros, se quejaban de que "el movimiento [no había sido] comprendido por la mayoría de huelguistas, que solo [apreciaban] las ventajas materiales, en menoscabo de la dignidad" ("Termina el conflicto marítimo", 11 de agosto de 1923).

Pese a esto, el citado Gobernador mantuvo la determinación de no tolerar wobblies en las faenas 
de embarque. Razón por la que había citado en su despacho al jornalero Francisco Miranda durante mediados de año, para que optara "por la sociedad a que estaba afiliado o por la matrícula". Como Miranda se rehusara a abandonar la IWW, el gobernador marítimo, "concedióle un plazo de un mes quince dias para que buscase trabajo en otra parte". Pero Miranda no le obedeció, e inclusive fue incluido en la redondilla; cosa que notó el inspector de bahía, y al tratar este último de removerlo de las faenas, la cuadrilla paralizó el trabajo, desatándose la más larga de las huelgas portuarias del período ("Los conflictos marítimos", El Nacional, 22 de septiembre de 1923; "En las faenas marítimas", El Nacional, 21 de septiembre de 1923).

En la interpretación de los comunistas, no cabían dudas que se trataba del "afán de provocar [problemas] a fin de presentar el sistema de redondilla como fuente de conflictos", y señalaban, dando cuenta del crecimiento de la Unión Local: "estamos seguros que los gremios marítimos sabrán oponerse con altivez a las pretensiones de eliminar a un obrero por el hecho de pertenecer a esta organización, a la cual pertenece la mayoría de los trabajadores de la bahía" ("Un nuevo conflicto marítimo", El Despertar de los Trabajadores, 23 de septiembre de 1923; "La huelga general de la bahía y la ribera debe ser coronada por un brillante triunfo", El Despertar de los Trabajadores, 26 de septiembre de 1923). En efecto, para el día 25, tras hacerse general la huelga entre los jornaleros, secundados por los estibadores, lancheros y cargadores, el gobierno suprimió la redondilla, "[autorizando] a las casas embarcadoras para organizar por su cuenta las cuadrillas". Para inicios de octubre, cuando fueron allanados los locales del Gremio de Jornaleros y el de la Unión Local de la IWW, apresados treinta y tres trabajadores y destruida la imprenta donde se editaba El Productor, la prensa hostil a la huelga sostuvo con regocijo: "Apresados los elementos de la IWW los obreros tranquilos nada tienen que temer", "el Lunes se espera reanudar las faenas". Pero la paralización se prolongaría hasta mediados de diciembre, languideciendo progresivamente hasta su desfonde, tras noventa días ("La huelga toca a su fin", El Nacional, 5 de octubre de 1923; "Huelguistas, leed lo que os dice un compañero", El Nacional, 9 de octubre de 1923).

Este desenlace significó, en efecto, el aniquilamiento de la Unión Local iquiqueña, tras un dificultoso arraigo entre los gremios marítimos y portuarios. También del reordenamiento estatal de los sistemas de contratación en las faenas de estiba; cerrando con ello un ciclo de conflictividad laboral que se había tornado particularmente álgido desde 1919, pero que precedía a dicha coyuntura.

\section{Conclusiones}

El examen documental en los párrafos anteriores permitió observar los accidentados esfuerzos de enraizamiento que la IWW exhibió en la costa salitrera entre 1919 y 1923; siendo posible sostener, de modo opuesto a la historiografía precedente, que la IWW no contribuyó de modo significativo en la conflictividad laboral acontecida en los terminales marítimos nortinos sino hasta 1923, y exclusivamente en los muelles iquiqueños. En dicho puerto, con la posible excepción del segundo semestre de 1921, los wobblies no sostuvieron hegemonía alguna sobre la "gente de mar" durante 1919-1922. En Antofagasta, la misma apreciación se hace extensiva a toda la coyuntura 1919-1923, sin excepciones. En ambas provincias, y durante el transcurso de dicho período, los obreros portuarios y marítimos levantaron federaciones, asestaron severos golpes huelguísticos y consiguieron sus viejas demandas al margen de la IWW. El hecho de que la ofensiva patronal y estatal para recuperar el control de la contratación en Antofagasta, durante 1921, fuera dirigido contra los gremios abiertamente hostiles a los industrialistas porteños, corrobora dicha disociación.

¿Por qué motivos la historiografía erró en la atribución de la conflictividad laboral en los muelles nortinos? De acuerdo con lo que sugiere la revisión documental involucrada en este estudio crítico, parte de las imprecisiones historiográficas radica en la insuficiente exhaustividad y rigurosidad con que fueron examinadas las fuentes en las investigaciones precedentes; pues la documentación utilizada por dichas investigaciones no guarda diferencias importantes con la aquí empleada. En segundo término, la atribución únicamente coyuntural a la conflictividad referida parece originarse en la escasa consideración del itinerario reivindicativo de los obreros marítimos y portuarios desde fines del siglo XIX, atravesado por el persistente intento de derogación de los intermediarios en las faenas de estiba y la larga tradición huelguística que su posición disruptiva les facilitaba. Por último, la poca agudeza en la distinción de los diferentes oficios 
que componían la fuerza de trabajo en los muelles, bodegas y barcos, y de sus respectivos derroteros, tampoco habría facilitado el entendimiento de la complejidad que convivía bajo la común denominación de "gente de mar", en medio de esta la IWW bregó por arraigarse.

Tomando en cuenta este conjunto de factores, resulta comprensible que la expulsión del jornalero y wobblie Francisco Miranda, que desató la huelga larga de 1923, confundiera a los historiadores, haciéndoles suponer una "influencia" de mayor tiempo y profundidad a la que las fuentes concretamente indican. Todavía más considerando la explícita y deliberada intención gubernamental por aniquilar a la IWW de las faenas de estiba en Iquique. Sin embargo, el hecho de que esta organización le otorgara una página completa de El Productor al Gremio de Jornaleros de dicho puerto, poco antes de la referida huelga y no perteneciendo este a la IWW, pone de manifiesto una relación bastante más compleja. Prueba, por una parte, los esfuerzos de los wobblies por constituir fuerza obrera a partir de la unificación industrial, aunque fuese por fuera de la Unión Local, $\mathrm{y}$ evidencia igualmente las intenciones de los jornaleros por resguardar a toda costa las prerrogativas contractuales involucradas con el mantenimiento de la redondilla ("Nuestros propósitos", El Productor, 13 de septiembre de 1923). Relación de común interés, que cobraba particular sentido en el contexto postcrisis salitrera, de reanimación de la IWW y del inminente y perjudicial reordenamiento del sistema de contratación que regía a dichos obreros.

En los años anteriores, la relación entre la IWW y los gremios marítimos nortinos parece incluso haber sido inversa a la sugerida por los historiadores del movimiento obrero. Como fue señalado, la determinación de "Imponer [la redondilla]" que los industrialistas plantearon en su Segunda Convención de 1921, se hallaba ya instaurada en Iquique (1920) y Antofagasta (1919), y la resolución de abolir el sistema de contratistas en las faenas marítimas, planteada en la misma Segunda Convención, había sido acordada en la Convención de las Federaciones Obreras Marítimas de los mismos puertos, en 1920 (y también anteriormente, en 1917). Componiendo ambas cuestiones el nudo que caracterizó la conflictividad laboral del período, resulta obvio que fueron las demandas de los obreros marítimos nortinos las que nutrieron a la IWW; sin perjuicio que dichos obreros seguramente vieron la posibilidad de fortalecer y amplificar el radio de sus conquistas al alero de una organización nacional que no les resultaba incómoda (como sí habían manifestado respecto de la FOCH), simpatizaron con sus postulados de redención social, o comprendieron lo táctico de la propia práctica huelguística al leer o escuchar sobre el "industrialismo". Como fue señalado, sin embargo, dicho vínculo no se llegó a materializar antes de 1921, en un puerto en particular y con las limitantes intestinas y contextuales ya descritas.

No obstante, pese a que el Gremio de Jornaleros, beneficiario del sistema rotativo, no pertenecía por consiguiente a la Unión Local, y las huelgas portuarias que habían protagonizado precedían por largo tiempo y viejos motivos al arribo de los wobblies, los esfuerzos patronales y gubernamentales de 1923 procuraron suprimir la redondilla e infligirle al mismo tiempo un golpe fatal a la IWW, así como apuntaron Pinto y Valdivia (2001:94). Cuestión explicable por los recaudos respecto de la posible dirección que los industrialistas podían imprimirle a dichas paralizaciones; siendo, las medidas exigidas $\mathrm{y}$ tomadas por patrones y autoridades, un esfuerzo por arrancar el brote desde la raíz.

Ciertamente que este largo raigón gremial cobrara nombre y rostros, facilitó su conversión en objeto de represión. También en objeto de la historiografía. Los historiadores del movimiento obrero, sin embargo, parecen haber prestado desigual atención a brotes y raíces.

\section{Referencias Citadas}

Araya, M.

2008 Los wobblies criollos: Fundación e ideología en la Región chilena de la Industrial Workers of the World-IWW (1919-1927). Tesis para optar al grado de Licenciado en Historia, Universidad ARCIS, Santiago, Chile.

Barría, J.

1960 Los movimientos sociales en Chile desde 1910 hasta 1926 (Aspecto político y social). Memoria de prueba, Lic. Ciencias
Jurídicas y Sociales, Escuela de Derecho, Universidad de Chile, Editorial Universitaria, Santiago, Chile.

Barría, J.

1971 El movimiento obrero en Chile. Colección Trígono, Santiago.

Cole, $\mathrm{P}$.

2007 Wobblies on the Waterfront. Interracial Unionism in Progressive-Era Philadelphia. University of Illinois Press, Illinois. 
DeShazo, P.

1973 The Industrial Workers of the World in Chile, 19171927. M. A. Thesis, University of Wisconsin, Wisconsin, United States of America.

DeShazo, P.

1979 "The Valparaíso maritime strike of 1903 and the development of a revolutionary movement in Chile". Journal of a Latin American Studies 2 (1):145-168.

DeShazo, P.

2007 Trabajadores urbanos y sindicatos en Chile: 1902 1927. Centro de Investigaciones Diego Barros Arana de la Dirección de Bibliotecas, Archivos y Museos, Santiago.

Grez, S.

2007 De la "regeneración del pueblo" a la huelga general. Génesis y evolución histórica del movimiento popular en Chile (1810-1890). RIL Editores, Santiago.

Holley, $\mathrm{H}$.

1905 Las Huelgas. Memoria de Prueba para optar al grado de Licenciado en la Facultad de Leyes y Ciencias Políticas, Universidad de Chile, Santiago, Chile.

Iturriaga J.

1997 "La huelga de trabajadores portuarios y marítimos. Valparaíso, 1903, y el surgimiento de la clase obrera organizada en Chile". Tesis para optar al grado de Licenciado en Historia, Pontificia Universidad Católica, Santiago, Chile.

Jobet, J.

1951 Ensayo crítico del desarrollo económico-social de Chile. Editorial Universitaria, Santiago.

Jobet, J.

1955 Recabarren. Los orígenes del movimiento obrero y el socialismo chilenos. Prensa Latinoamericana, Santiago.

Kellerman, S.

2007 A Century of Writing on the IWW 1905-2005. An Annotated Bibliography of Books of the Industrial Workers of the World. Industrial Workers of the World, Boston General Membership Branch, Massachusetts.

Muñoz, V.

2013 Sin Dios ni patrones. Historia, diversidad y conflictos del anarquismo en la región chilena (1890-1990). Mar y Tierra Ediciones, Valparaíso.

Ortiz, F.

1985 El movimiento obrero en Chile, 1891-1919, Ediciones Michay, Madrid.

Parker, C., Valenzuela, S. y Ávalos, G.

1985 Perspectiva del desarrollo histórico de las organizaciones de los obreros marítimos chilenos. Memoria para optar al título de Profesor de Estado en Historia y Geografía, Universidad Católica de Valparaíso, Valparaíso, Chile.

Pinto, J.

1998 Trabajos y rebeldías en la pampa salitrera. El ciclo del salitre y la reconfiguración de las identidades populares (1850-1900), Editorial USACH, Santiago.

Pinto, J. y Valdivia, V.

2001 ¿Revolución proletaria o querida chusma? Socialismo y Alessandrismo en la pugna por la politización pampina (1911-1932). LOM Ediciones, Santiago.

Ramírez, H.

2007 Historia del Movimiento obrero en Chile, Antecedentes - Siglo XIX. Obras Escogidas, Volumen I, LOM Ediciones, Santiago.
Ramírez, H.

2007 Origen y formación del Partido Comunista de Chile. Ensayo de historia política y social de Chile. Obras Escogidas, Volumen II, LOM Ediciones, Santiago.

Recabarren, F.

1954 Historia del proletariado de Tarapacá y Antofagasta (1884-1913). Memoria de prueba para optar al título de Profesor de Historia, Geografía y Educación Cívica, Universidad de Chile, Santiago, Chile.

Saavedra, A.

2005 La IWW y su rol en el movimiento obrero. Valparaíso, Iquique y Antofagasta (1919-1927). Tesis para optar al grado de Licenciado en Educación con mención en Historia y Geografía, Universidad de Santiago de Chile, Santiago, Chile.

Santibáñez, C.

2015 Huelgas y lockouts portuarios por 'la redondilla': Los conflictos por la contratación en los muelles chilenos (1919-1923). Tesis para obtener el grado de Magíster en Historia, mención Historia de Chile, Universidad de Santiago de Chile, Santiago, Chile.

Santibáñez, C.

2017 "Los trabajadores portuarios chilenos y la experiencia de la eventualidad: Los conflictos por la redondilla en los muelles salitreros (1916-1923)", Historia 50, Santiago (en prensa).

Vitale, L.

2011 Interpretación marxista de la Historia de Chile. Volumen III, LOM Ediciones, Santiago.

Yávar, A

1989 "El gremio de los jornaleros y lancheros de Valparaíso, 1837-1859. Etapa de formación”, Historia 24:319-395, Santiago.

\section{Fuentes documentales y archivísticas}

\section{Periódicos}

El Despertar de los Trabajadores (Iquique)

El Nacional (Iquique)

El Productor (Iquique)

El Sembrador (Iquique)

El Socialista (Antofagasta)

El Surco (Iquique)

La Jornada (Coronel)

La Unión (Valparaíso)

\section{Archivos}

Archivo de la Intendencia de Tarapacá.

Archivo Nacional de la Administración, Oficina del Trabajo.

\section{Otras fuentes}

"El movimiento en Pisagua. La verdad en su lugar", Federación Obrera Marítima de Pisagua, Iquique, 7 de mayo de 1923 (documento inédito).

Oyarzún, E, Concha, J. E. y Philippi, J.

1917 Informe presentado al Supremo Gobierno sobre las huelgas de Iquique en 1916. Santiago de Chile. 


\section{Notas}

1 Este artículo está basado en la ponencia "Notas críticas sobre el estudio histórico de la IWW y el movimiento obrero chileno a partir de un estudio de caso: Los estibadores del salitre (1919-1923)", presentada en el IV Congreso de Estudiantes de Historia, organizado por la Universidad Católica de Chile y la Universidad Alberto Hurtado, el 11 y 12 de octubre de 2016 en Santiago de Chile.

2 De los textos clásicos acerca del movimiento obrero, han sido revisados las siguientes obras: Jobet 1951, 1955; Barría 1960, 1971; Ramírez 2007; Ortiz 1985; y Vitale 2011. Sobre la IWW en Chile, pueden consultarse los siguientes trabajos: DeShazo 1973; Saavedra 2005; Araya 2008; y Muñoz 2013:107-117. Sobre la IWW en general, una bibliografía abundante se puede consultar en la compilación de Steve Kellerman 2007; en lo que respecta a la IWW en las faenas de estiba, la obra más importante, y no incluida en Kellerman, es Cole 2007. Las huelgas marítimas y portuarias de Valparaíso a las que se alude, por otra parte, son trabajadas en DeShazo 2007:257-276.

3 La redondilla fue un sistema de repartición rotativa de los turnos entre los obreros que componían la fuerza de trabajo en las faenas de estiba, con el propósito de sortear la arbitrariedad con que los intermediarios elegían a determinados hombres en perjuicio de otros. El poder que confería la atribución de seleccionar a los obreros que conformarían la redondilla, y por tanto tendrían trabajo, confrontó a obreros, intermediarios, casas exportadoras y al gobierno chileno entre 1916 y 1923 . La conflictiva historia de este sistema de contratación es examinada en Santibáñez 2015 y Santibáñez 2017.

4 Respecto de los gremios portuarios decimonónicos ver: Grez 2007:258-268 y 462-470; Parker et al. 1985:11-25; y Yávar 1989.

5 Habitualmente, las causas de la huelga porteña han sido reducidas a demandas salariales. Sin embargo, es posible dar cuenta de indicios importantes en otra dirección. Según la respuesta patronal a los petitorios obreros, documentada por un trabajo académico contemporáneo, los lancheros estaban planteando "monopolizar el trabajo en la bahia i establecer una oficina de recontrolación que [interviniera] en los pagos". Los estibadores habían propuesto "nombrar ellos [a los] capataces o inspectores" e igualmente "crear [una] oficina recontroladora, que escoja o designe la jente, fije los sueldos [y] reglamente el trabajo". Los tripulantes, en tanto, habían solicitado "que los vapores sean tripulados especialmente por los reclamantes o sus consocios". En opinión de las compañías, los trabajadores estaban intentando "[gozar] de un monopolio sin base en la razon ni en la lei, a virtud del cual ellos, simples trabajadores remunerados, pasarian a ser dueños absolutos de la empresa o compañia que remunera su trabajo, haciendo desaparecer la autoridad, el órden i la disciplina" (Holley 1905:22-32). Entre otros textos, esta huelga ha sido eje de trabajos como: Iturriaga 1997 y DeShazo 1979.

6 Prácticamente en paralelo, acusando "la actitud despótica de los contratistas", la Unión de Estibadores y Gente de Mar de Valparaíso envió una nota al gobernador marítimo indicando que "había iniciado las gestiones para la instalación de una Oficina del Trabajo [que] se haría cargo del nombramiento de las cuadrillas de las faenas marítimas" (Parker et al. 1985:75).

7 En su tesis de licenciatura, Mario Araya (2005) relata el proceso de empuje organizacional por el que atravesó la IWW en los años 1917-1919, particularmente en el capítulo I.

8 Acerca de la ofensiva patronal ver: "El lock-out en la bahía", La Unión, 18 y 24 de agosto de 1921.

9 Para marzo del aquel año, el mismo periódico refiere la apatía de los cargadores, por limitarse a pagar las cuotas ("A mis compañeros cargadores", 3 de marzo de 1923; "Al gremio de cargadores", 27 de enero de 1923).

10 Sobre las Subdivisiones formadas ver: "El conflicto de la casa Granja", El Sembrador, 17 de marzo de 1923; ITAR 1203, legajo 147; "Nigromancia comunista", El Sembrador, 24 de marzo de 1923; "Nuestro frente de combate", El Productor, 31 de marzo de 1923. Sobre la huelga de Pisagua: "El estado de sitio en Pisagua", El Despertar de los Trabajadores, 15 de mayo de 1923. Ver también: "Solicitada", El Sembrador, 30 de junio de 1923. 